\title{
Arms regeneration in the squid Lolliguncula panamensis (Mollusca: Cephalopoda)
}

\author{
Sairi Saraí León Guzmán ${ }^{1} \&$ María del Carmen Alejo-Plata ${ }^{2}$ \\ ${ }^{1}$ Posgrado en Ecología Marina, Universidad del Mar Campus Puerto Ángel, Oaxaca, México \\ ${ }^{2}$ Instituto de Recursos, Universidad del Mar Campus Puerto Ángel, Oaxaca, México \\ Corresponding author: María del Carmen Alejo-Plata (plata@angel.umar.mx)
}

\begin{abstract}
During two sampling trips carried out over the continental platform of Gulf of Tehuantepec, a total of 101 Lolliguncula panamensis Berry, 1911 were caught. Thirty mature specimens (19 females and 11 males) were found to have unusually short arms. Dorsal mantle length, arm's length, and body weight were measured from the fresh specimens. Evidence of regeneration was observed at different points along arms; these may have been the result of partial autonomies. In the injured arms, the surface of the arm's tip was wholly covered with skin. Fracture planes were found in our histological sections; the autotomized arms exhibited constricted muscle fibers in the longitudinal sections indicative of wound closing. The arms of the specimens observed were very similar to the regenerating arms of other squids. This study represents the first to report arms regeneration and hectocotylus in this squid wild-caught. These results suggest that Lolliguncula panamensis exhibit partial autotomy, and the ability to regenerate the arms. Additionally, each of the eight arms can do so, presumably during defensive interaction or mating.
\end{abstract}

Keywords: Lolliguncula panamensis; Loliginidae; arm regeneration; autotomy; Gulf of Tehuantepec

Lolliguncula panamensis Berry, 2011 is distributed in the Eastern Pacific from the Gulf of California, Mexico to Peru (Roper et al., 1995), and principally inhabits depths of less than $45 \mathrm{~m}$ (Sánchez, 2003). This species is a highly opportunistic predator foraging primarily in coastal and epipelagic waters (Arizmendi-Rodríguez et al., 2011). In Mexico, this species is recurrent in the bycatch of the shrimp trawl fishery (Alejo-Plata et al., 2001); however biological information for this species is scarce.

Two sampling trips were carried out during November-December 2017 and May 2018 to the Gulf of Tehuantepec between Salina Cruz (16 $08^{\prime} 29^{\prime}$ 'N, $\left.95^{\circ} 10^{\prime} 50^{\prime \prime} \mathrm{W}\right)$ and Barra de Suchiate $\left(16^{\circ} 13^{\prime} 00^{\prime \prime} \mathrm{N}\right.$, $92^{\circ} 14$ '30'W) (Fig. 1). A total of 55 bottom trawls were carried out at a depth of 14.7 to $42.8 \mathrm{~m}$ using trawl nets with a $52.5 \mathrm{~mm}$ mesh size. A total of 101 L. panamensis were caught.

Thirty mature specimens ( 19 females and 11 males) were found to have unusually short arms. Dorsal mantle length (ML), arm's length (AL), and body weight (BW) were measured from the fresh specimens (Roper \& Voss, 1983). Stages of arm regeneration were determi- ned according to the criteria of Tressler et al. (2014): frayed edge (I), smooth edge (II), growth bud appearance (III), tip emergence (IV), and tip elongation (V). Whole individuals were frozen and later fixed in $10 \%$ neutral buffered formalin in seawater tallowed by preservation in $70 \%$ ethanol. Ten arms were dehydrated in a graded alcohol series, cleared with citrosol and embedded in paraplast. Longitudinal sections of six micros thick were made a Leica rotating microtome and stained with hematoxylin-eosin and with Massons trichrome (Bancroft et al., 1990).

The proportion of regeneration was of $19 \%$ females and $10 \%$ males. Nineteen females had a total of $50 \mathrm{arms}$ in regeneration (33\%) and 11 males with 48 arms in regeneration (60\%) (Table 1). Arm regeneration in ale may be important because the arms play an important role in grasping the female during mating in this species.

In females, L4 (left arm 4 length) and R4 (right arm 4 length) were most frequently lost; in males, L2 and R3 were most frequently lost while L4 (hectocotylus) and R4 were least frequently missing (Fig. 2). An accident likely relates the unusual shortness of the arms 


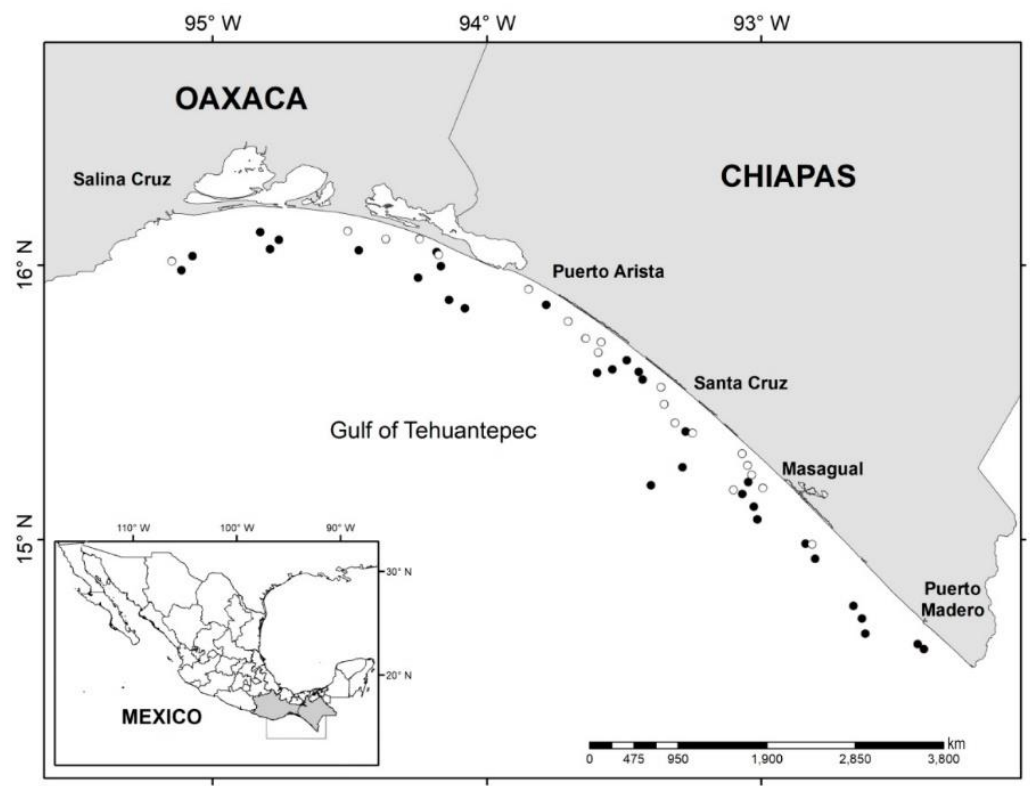

Figure 1. Study area with locations of 58 bottoms trawls (black dots). White dots indicate records of Lolliguncula panamensis.

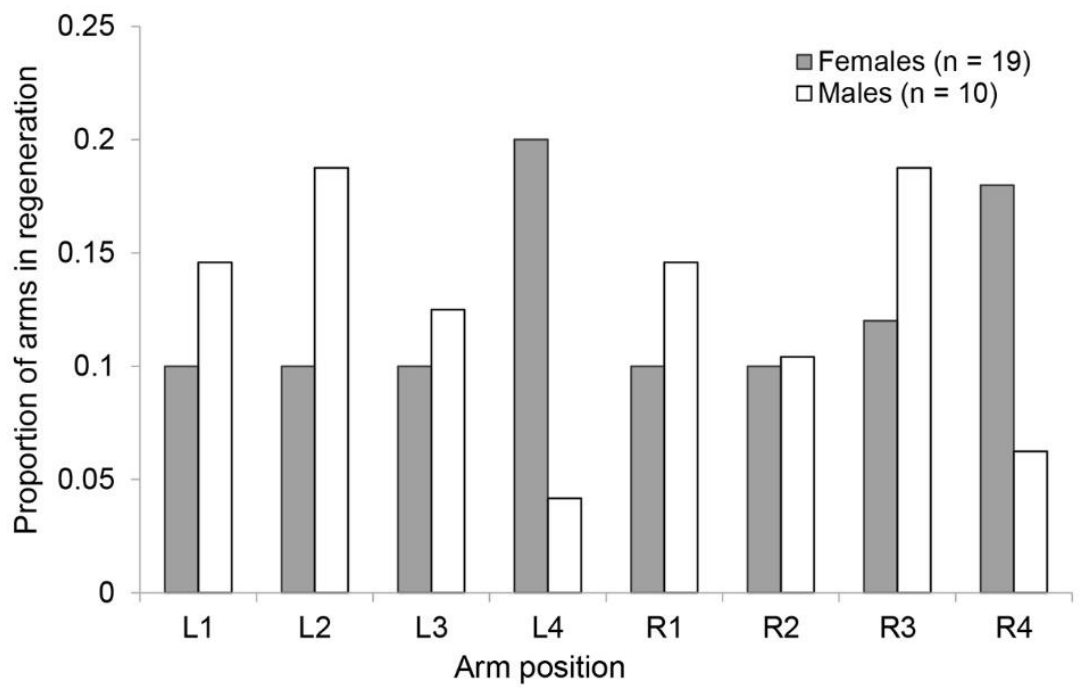

Figure 2. Lolliguncula panamensis. Arm positions (L1-L4, R1-R4) that are most often autotomized (regeneration arm stub) in the Gulf of Tehuantepec. L: left; R: right.

(e.g., feeding, fighting, jigging) (Ikeda et al., 2004) or with predator avoidance (Bush, 2012). The hectocotylized arm was less susceptible to injury in comparison to other arms (Fig. 2) as was observed by Bello (1995) for bobtail squids; apparently, only the tip of the hectocotylus was involved in the traumatic loss and subsequent regeneration process. Besides, protection and more rapid regeneration of this specialized arm to be due to its importance in mating (Wada, 2017).

Evidence of regeneration was observed at different points along arms from $L$. panamensis; these may have been the result of partial autotomies. In the injured arms, the surface of the arm's tip was completely covered with skin (Fig. 3). Fracture planes were observed; the autotomized arms exhibited constricted muscle fibers in the longitudinal sections, indicative of wound closing, and cells with dark pink nuclei concentrated at the edges of both ends of arm tissue were observed (Fig. 4). This study represents the first to report for arms regeneration and hectocotylus in $L$. panamensis wild-caught. The arms of the specimens observed were very similar to the regenerating arms of other squids (Bello, 1995; Bush, 2012). 


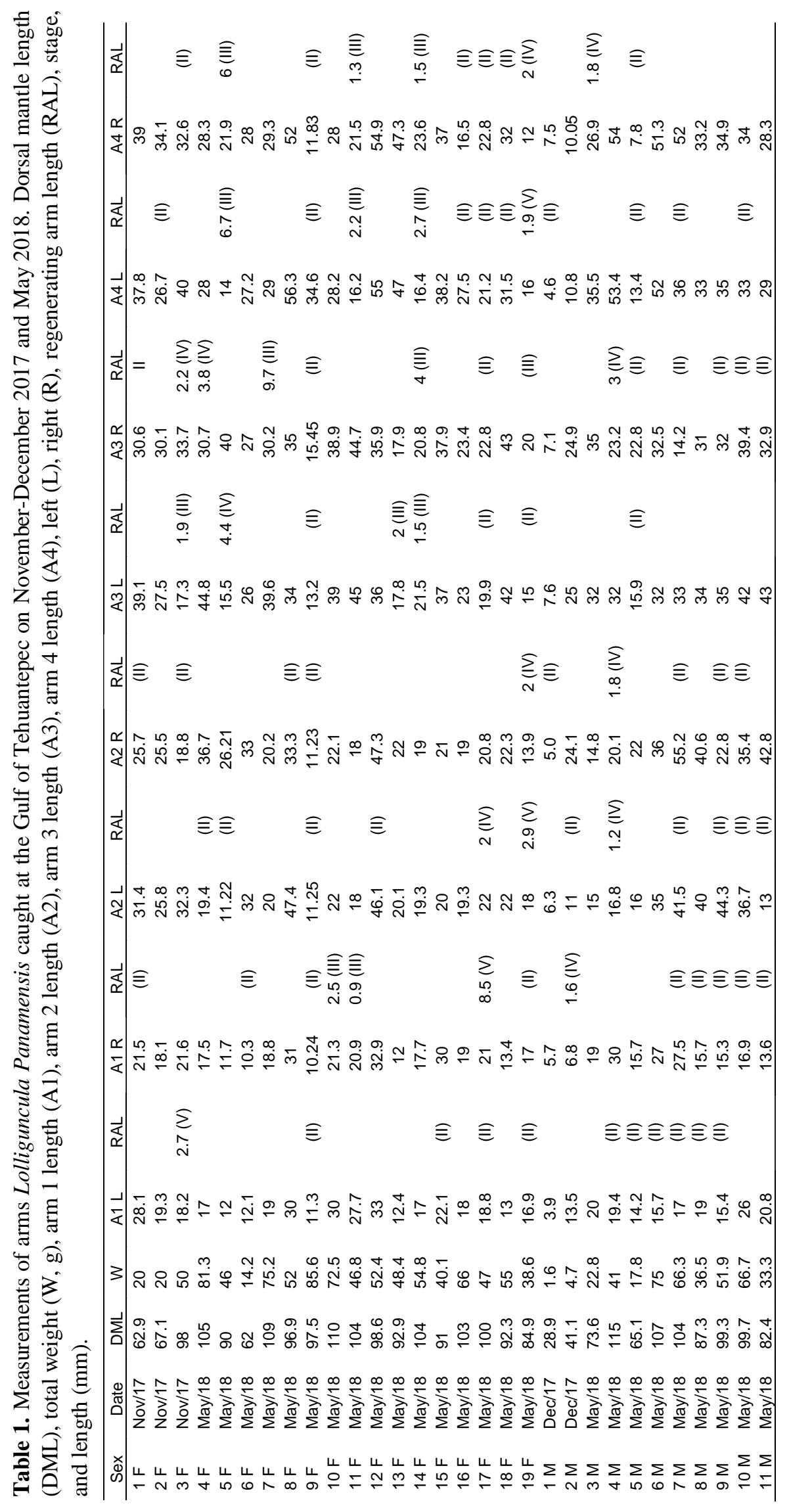




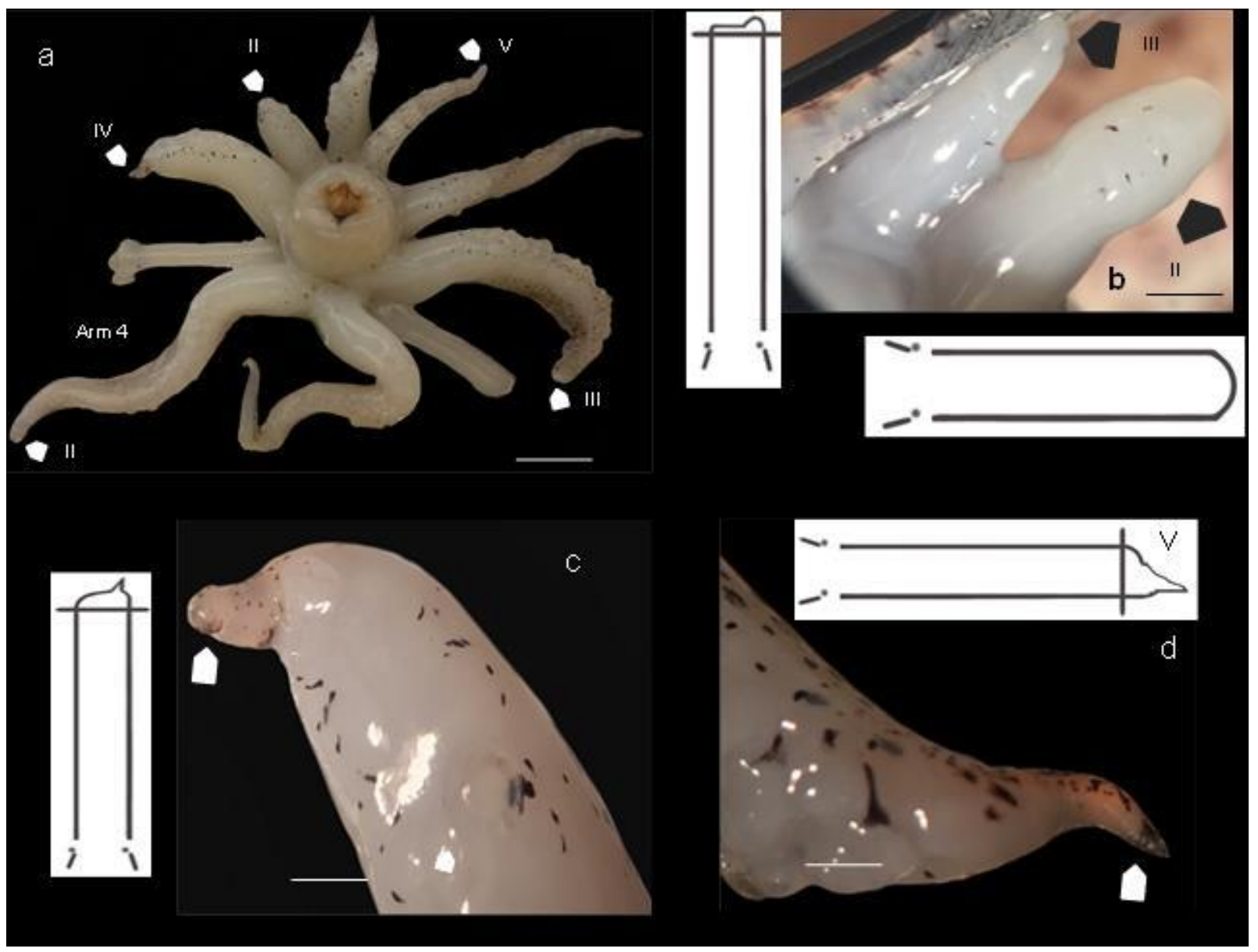

Figure 3. Arms regeneration stages in Lolliguncula panamensis. a) Oral view of arms in female $98 \mathrm{~mm}$ DML; b) Stage II: the leading edge of the regeneration arm exhibits a smooth hemispherical appearance, and suction cups first appear during this stage; stage III: a growth bud emerges at the start of this stage; d) Stage IV: elongated tip extends from the growth bud; e) Stage V: elongated tip takes on a tapered appearance closely resembling the tip of an intact arm. Scale bar $=27 \mathrm{~mm}$ a) and d); $12 \mathrm{~mm} \mathrm{c}$ ) and b); $51 \mathrm{~mm} \mathrm{e}$ ).

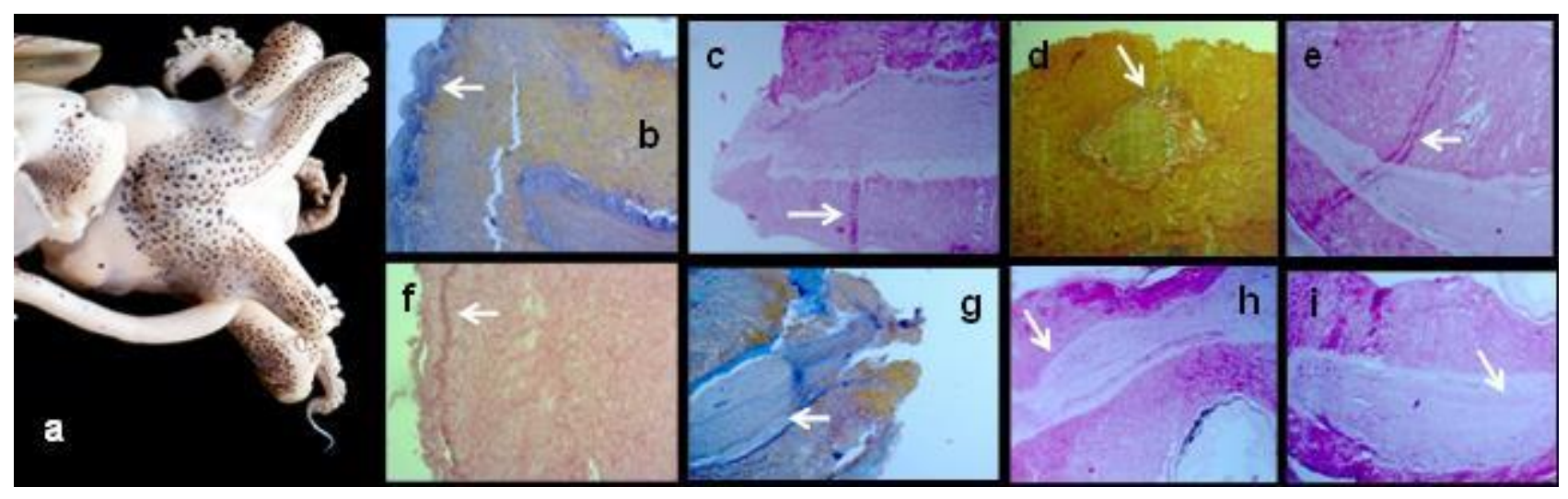

Figure 4. Lolliguncula panamensis. a) Female with arms autotomized (LM $=84.9 \mathrm{~mm})$, b) autotomized end of the first (L1, II), fracture plane where the arm autotomized (arrow). Longitudinal sections through the regeneration zone, arrow showing the plane where autotomy occurs: c) arm L2 (V); d) arm R2 (IV); e) arm R4 (IV); f) autotomized end of the third (R3, III) lost arm. Damage in the arm, possibly from partial autotomy, that has been regenerated (arrow); g) arm R2 (IV); h) arm L4 (V). Male with arms autotomized, $(\mathrm{LM}=115 \mathrm{~mm})$, i) longitudinal sections through the regeneration zone arm R2 (IV). Histological sections stained with hematoxylin-eosin (c, e, g, i), and Massons trichrome (b, d, f, h) 10x. 
Cephalopods are soft-bodied invertebrates; in them, the regeneration is common (Imperadore \& Fiorito, 2018 summarize the information on regeneration). They have even evolved the ability to autotomize and to regenerate the lost appendages subsequently (Wada, 2017). Autotomy is typically a last resort defense in predator-prey interactions since it involves the loss (Fleming et al., 2007). Some shallowwater octopuses autotomize and regenerate arms (Norman, 1992; Wada, 2017); other octopuses autotomize at a preformed fracture plane or also have a specific section along the arm (Norman, 1992). The squid Octopoteuthis deletron is the first cephalopod species reported to be capable of exhibit 'economy of autotomy'; the ability to vary the detachment site according to the amount of appendage lost to the predator. For example, has numerous places where an arm can sever; arms breakage always occurred immediately proximal to the point of interaction, minimizing tissue loss (Bush, 2012), and thereby reducing the associated costs of this defense, while still allowing escape (Fleming et al., 2007).

Our results suggest that Lolliguncula panamensis exhibit partial autotomy, and the ability to regenerate the arms. Additionally, each of the eight arms can do so, presumably during defensive interaction or mating.

\section{ACKNOWLEDGMENTS}

The authors would like to thank the Centro Regional de Investigaciones Pesqueras of Salina Cruz for support in collecting organisms. We thank Hugo Guzmán Intzin for collecting samples. This study was supported by Consejo Nacional de Ciencia y Tecnología (CONACyT- PDCPN 2015-1740), MCAP is thankful SNI-CONACyT program. This manuscript has been improved by comments and suggestions from anonymous reviewers

\section{REFERENCES}

Alejo-Plata, M.C., Cerdenares-Ladrón de Guevara, G. \& Herrera-Galindo, J.E. 2001. Cefalópodos loligínidos en la fauna de acompañamiento del camarón. Ciencia y Mar, 5: 41-46.

Arizmendi-Rodríguez, D.I., Cruz-Escalona, V.H., Quiñónez-Velázquez, C. \& Salinas-Zavala, C.A. 2011. Feeding habits of the Panama brief squid (Lolliguncula panamensis) in the Gulf of California, Mexico. Canadian Journal of Fisheries and Aquatic Sciences, 6(2): 194-201.

Received: 10 April 2018; Accepted: 8 October 2018
Bancroft, J.D., Stevens, A. \& Turner, D. 1990. Theory and Practice of Histological Techniques. Great Britain, $726 \mathrm{pp}$.

Bello, G. 1995. Hectocotylus regeneration in wild-caught sepiolid squids. Journal of the Marine Biological Association of the United Kingdom, 75(2): 491-494.

Bush, S. 2012. Economy of arm autotomy in the mesopelagic squid Octopoteuthis deletron. Marine Ecology Progress Series, 458: 133-140.

Fleming, P.A., Muller, D. \& Bateman, P.W. 2007. Leave it all behind: a taxonomic perspective of autotomy in vertebrates. Cambridge Philosophical Society, 82: 481-510.

Ikeda, Y., Kidokoro, H. \& Uji, R. 2004. Notes on an exhausted Japanese common squid, Todarodes pacificus (Cephalopoda: Ommastrephidae), with an unusually short arm. Bulletin of the College of Science, 77: 143-147.

Imperadore, P. \& Fiorito, G. 2018. Cephalopod tissue regeneration: consolidating over a century of knowledge. Frontiers in Physiology, 23(9): 593.

Norman, 1992. Ameloctopus litoralis gen. et sp. nov. (Cephalopoda: Octopodidae), a new shallow-water octopus from tropical Australian waters. Invertebrate Taxonomy, 6: 567-582.

Roper, C.F.E. \& Voss, G.L. 1983. Guidelines for taxonomic descriptions of cephalopod species. Memoirs of Museum Victoria, 44: 49-63.

Roper, C.F., Sweeney, M. \& Hochberg, F. 1995. Cephalopods. In: Fisher, W., Krupp, F., Sommer, C., Carpenter, K. \& Niem, E. (Eds.). Guía FAO para la identificación de especies para los fines de pesca. Pacífico Centro-Oriental, plantas e invertebrados. Organización de las Naciones Unidas para la Alimentación y la Agricultura, Rome, pp. 235-253.

Sanchez, P. 2003. Cephalopods from off the Pacific coast of Mexico: biological aspects of the most abundant species. Scientia Marina, 67(1): 81-90.

Tressler, J., Maddox, F., Goodwin, E., Zhang, Z. \& Tublitz, N. 2014. Arm regeneration in two species of cuttlefish Sepia officinalis and Sepia pharaonis. Invertebrate Neuroscience, 14: 37-49.

Wada, T. 2017. Size-assortative mating and arm loss in the wild shallow-water octopus Abdopus sp. (Cephalopoda: Octopodidae). Journal of Natural History, 51: 2635-2644. 